\title{
ARTIGOS
}

\section{CRIACÃO DE CARTAZES COMO FERRAMENTA PARA DIMINUIÇÃO DO USO EXCESSIVO DE COPOS PLÁSTIICOS DESCARTÁVEIS}

\section{CREATING POSTERS AS A TOOL TO DECREASE THE OVERUSE OF DISPOSABLE PLASTIC CUPS}

\author{
ELIANA PAULA CALEGARI, Dra. | IFRO \\ VICTOR HUGO SOUZA CEZAR | IFRO
}

\begin{abstract}
RESUMO
O objetivo deste trabalho foi à criação e o desenvolvimento de cartazes como ferramenta para a conscientização da diminuição do uso excessivo de copos plásticos descartáveis. Para isso, foi utilizada a metodologia da área de design gráfico proposta por Fuentes (2006) que possui as seguintes etapas: pesquisa, concepção e concretização. Na primeira etapa da metodologia, a pesquisa, foram analisados cartazes similares com base nos princípios do design gráfico elaborados por Williams (2009). Na segunda etapa, a concepção, foi definido o tema do projeto, montados os painéis de imagens e realizada a geração de alternativas. Na última etapa, foi realizada a finalização dos cartazes. Como resultado, foi desenvolvido um exercício projetual em que se buscou propor cartazes que sugerem o uso de canecas para substituir os copos plásticos descartáveis.
\end{abstract}

PALAVRAS CHAVE: Design gráfico; Cartazes; Copo plástico descartável.

\begin{abstract}
The objective of this work was the creation and development of posters as a tool to raise awareness of the reduction of overuse of disposable plastic cups. For this, we used the methodology of graphic design area proposed by Fuentes (2006) which has the following steps: research, conception and implementation. In the first stage of the methodology, the research, similar posters were analyzed based on the principles of graphic design elaborated by Williams (2009). In the second stage, the conception, the project theme was defined, the image panels were assembled and alternatives were generated. In the last stage, the posters were finalized. As a result, a design exercise was developed in which posters were proposed that suggested the use of reusable mugs to replace disposable plastic cups.
\end{abstract}

KEY WORDS: Graphic design; Posters; Disposable plastic cup. 


\section{INTRODUÇÃO}

Mais de $95 \%$ do lixo encontrado nas praias brasileiras é composto por itens feitos de plástico, como garrafas, copos descartáveis, canudos, cotonetes, embalagens e outros (FAPESC, 2018). O consumo desenfreado do plástico têm causado sérias consequências ao meio ambiente, visto que esse material demora muito tempo para decompor-se na natureza. Um grave problema causado pelo plástico é a poluição marinha, em que os animais confundem o material plástico com comida, o que pode ocasionar a morte desses animais e deixá-los em risco de extinção (UNESC, 2019).

Atualmente, é muito comum o uso de copos plásticos descartáveis em instituições públicas e privadas devido à praticidade proporcionada por esse produto. Em geral, esses copos são utilizados uma única vez e descartados, ocasionando um grande acúmulo de resíduos no meio ambiente. De acordo com Bee Green (2019) o Brasil produz cerca de 100 mil toneladas de copos plásticos por ano.

Os copos plásticos descartáveis são produzidos com um material chamado poliestireno, que permite a reciclagem, no entanto, torna-se economicamente pouco viável, pois é uma matéria prima de baixo custo, e a outra dificuldade é que em geral, os copos plásticos são descartados sujos, o que dificulta o processo de reciclagem (ECYCLE, 2019).

Para a diminuição do uso excessivo de copos plásticos descartáveis e do acúmulo no meio ambiente, é necessária à criação de alternativas para conscientização da sociedade sobre os malefícios para o meio ambiente. Assim, neste trabalho buscou-se abordar a questão da conscientização da diminuição do uso de copos plásticos descartáveis por meio da criação de cartazes. O projeto de criação dos cartazes foi desenvolvido utilizando a metodologia projetual da área de design gráfico, de Fuentes (2006), e teve como suporte teórico o manual "design para quem não é designer" de Robin Williams, o qual possui noções básicas de planejamento visual.

\section{METODOLOGIA}

O desenvolvimento deste projeto teve como base a metodologia projetual de Fuentes (2006), que objetiva nortear o processo criativo do design. A seguir, é descrita a metodologia:

- Etapa I - A pesquisa: Esta etapa consiste na pesquisa sobre os elementos do design gráfico tendo como base a obra de Williams (1995) e a pesquisa de cartazes similares, ou seja, que possuem a temática da diminuição do uso de copos plásticos descartáveis. Nos cartazes foram analisados os seguintes elementos do design gráfico: contraste, proximidade, repetição, alinhamento, cores, tipografia, diagramação, ilustração e outros.
-Etapa II - A concepção: Nesta etapa foi realizada a pesquisa de imagens sobre o tema do projeto e montado um painel com elas para ser utilizado como referência para a geração de alternativas. Para a geração de alternativas foram feitos esboços à mão livre seguindo o tema do projeto.

- Etapa III - A concretização: Nesta etapa os esboços feitos à mão livre foram digitalizados, e a partir disso, foi realizada a ilustração digital no software Inkscape. Além disso, foram definidas as cores, a tipografia, o alinhamento, o contraste, a repetição, a proximidade, o suporte, e outros elementos do design gráfico necessários para a finalização dos cartazes. Por fim, os cartazes foram impressos e foi realizada a simulação de uso.

\section{DESENVOLVIMENTO}

\subsection{Etapa I - A pesquisa}

A NBR 15575-1 (2013) possui um procedimento para a anáNesta etapa foi realizada uma pesquisa sobre os princípios do design gráfico para auxiliar o processo de criação e desenvolvimento dos cartazes. Dessa forma, a seguir é apresentada uma abordagem genérica dos quatro princípios do design gráfico de acordo com Williams (2009):

a) Contraste: O objetivo do contraste é evitar os elementos parecidos em uma página. Assim, se os elementos como, cor, tipografia, tamanho, espessura da linha e espaço não forem os mesmos, é importante diferenciá-los.

b) Repetição: Repetir os elementos visuais de forma planejada pode ajudar a criar uma organização no layout e fortalecer a unidade. Pode-se optar por repetir diversos elementos, como: a cor, a espessura, a textura, o tamanho e outros.

c) Alinhamento: Nenhum elemento deve ser colocado aleatoriamente em uma página, assim, cada elemento deve estar relacionado visualmente com outro, isso vai ajudar a criar uma aparência limpa, organizada, sofisticada e suave.

d) Proximidade: Quando vários itens estão próximos, tornam-se uma unidade visual e não várias unidades individualizadas, por isso, itens relacionados entre si devem ser agrupados, o que vai ajudar a organizar as informações e diminuir a desordem.

e) Tipologia: $\mathrm{O}$ objetivo do uso de fontes diferentes é aperfeiçoar a comunicação, porém, se não for organizada corretamente pode confundir o leitor, assim, é importante tomar cuidado ao utilizar muitos tipos de fontes em um material. 
Neste trabalho serão utilizados os 5 princípios do design gráfico proposto por Williams (1995) para a criação da série de cartazes sobre a conscientização da diminuição do uso excessivo de copos descartáveis, garantindo assim, uma boa organização e melhor entendimento do cartaz.

Além disso, nesta etapa foi realizada uma pesquisa na internet sobre cartazes com a temática da diminuição do uso de copos plásticos descartáveis. Para isso foram utilizadas as seguintes palavras chaves: cartaz sobre o meio ambiente, peças gráficas sobre o meio ambiente, cartaz sobre o uso de copo plástico.

$\mathrm{Na}$ Figura 1 observa-se o cartaz produzido para a prefeitura municipal de Roque Gonzales/RS para uma campanha interna, que buscou a redução do uso de copos plásticos descartáveis. No cartaz observa-se o título, textos, a imagem da metade de um copo descartável e de uma caneca que aparenta ser de cerâmica. O cartaz está dividido em duas partes: de um lado com o título "evite copos descartáveis" e do outro lado o título "resgate sua caneca", essa divisão denota o uso do descartável (copo plástico) e do durável (caneca de cerâmica). Em relação aos princípios do design gráfico, observam-se as imagens no centro e os elementos escritos nas laterais, sobre o alinhamento foi empregado o centralizado. No cartaz o contraste que prevalece é do título, com letras na cor branca e fundo rosa de um lado e verde do outro lado. A fonte e o alinhamento são repetidos nos dois lados do cartaz. Por fim, em relação à cor, foi empregada a cor rosa de um lado e verde do outro lado, que pode sugerir o uso da caneca ao invés do copo plástico.

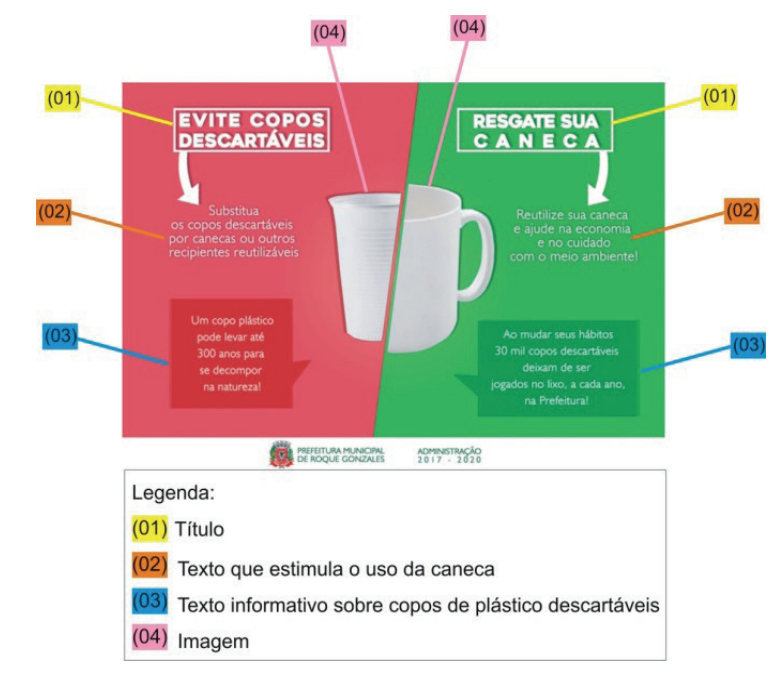

Figura 01 - Análise de cartaz

Fonte: Adaptada de Roque Gonzales (2019).

Na Figura 2 observa-se o cartaz criado pela Secretaria de Agricultura do município de Triunfo/RS para uma campanha de conscientização do não uso de copos plásticos descartáveis. No cartaz observa-se o título, textos, a imagem da metade de um copo descartável e a imagem de uma caneca que aparenta ser de cerâmica (TRIUNFO, 2019). O cartaz está dividido em duas partes: de um lado com o título "evite usar copo descartável" e do outro lado o título "use recipiente reutilizável", essa divisão denota o uso do descartável (copo plástico) e do durável (recipiente reutilizável). Em relação aos princípios do design gráico, observa-se que foram empregados de forma similar aos do cartaz da Figura 1, assim, observam-se as imagens no centro e os elementos escritos dispostos nas laterais, sobre o alinhamento foi utilizado o centralizado para a imagem e o alinhamento a esquerda para o título e o texto. No cartaz o contraste que prevalece é o do título, com letras na cor azul e fundo amarelo de um lado e letras na cor branca e fundo azul do outro lado, que sugere o uso da caneca ao invés do copo plástico.

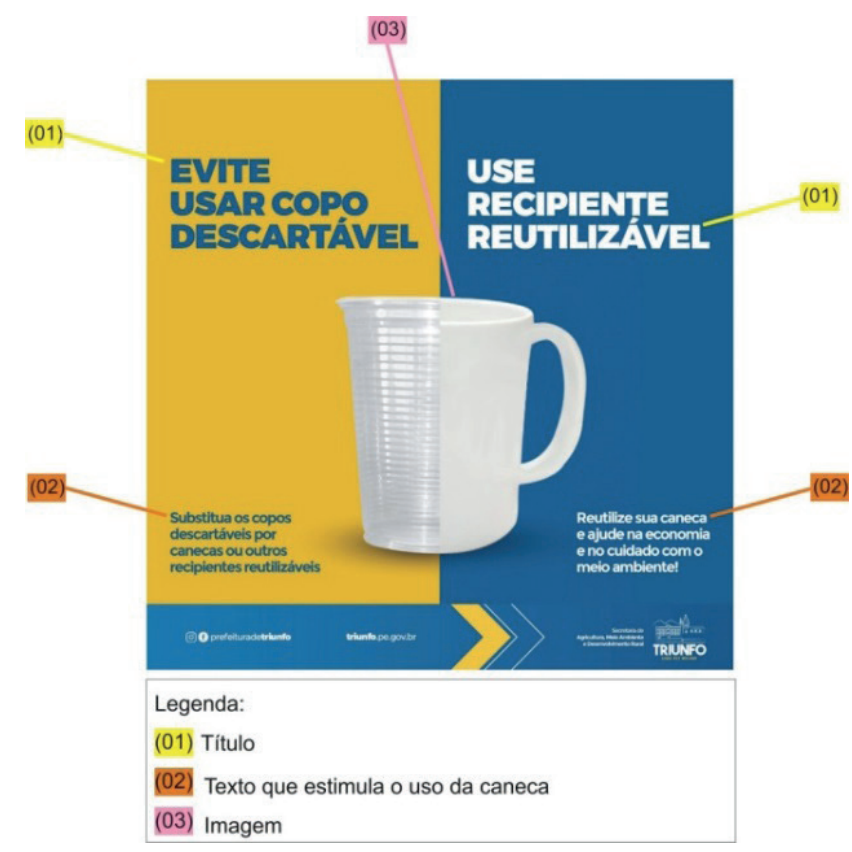

Figura 02 - Análise de cartaz

Fonte: Triunfo (2019).

Na Figura 3 observa-se o cartaz confeccionado para a Universidade Federal do Oeste do Pará para uma campanha de conscientização para o não uso de copos plásticos descartáveis, sugerindo o uso de canecas. No cartaz observa-se o título, a imagem de duas canecas na cor verde sobre o fundo branco que gera destaque para as canecas, na caneca do lado esquerdo observa-se o desenho de uma árvore, na outra caneca há a seguinte mensagem: "não ao copo descartável, o meio ambiente agradece". Em relação aos princípios do design gráfico, observam-se os elementos muito próximos, 
com o alinhamento à direita. $\mathrm{O}$ contraste que prevalece no cartaz é do título, pois está com fonte maior em relação aos outros elementos, e na cor azul escura com fundo verde.

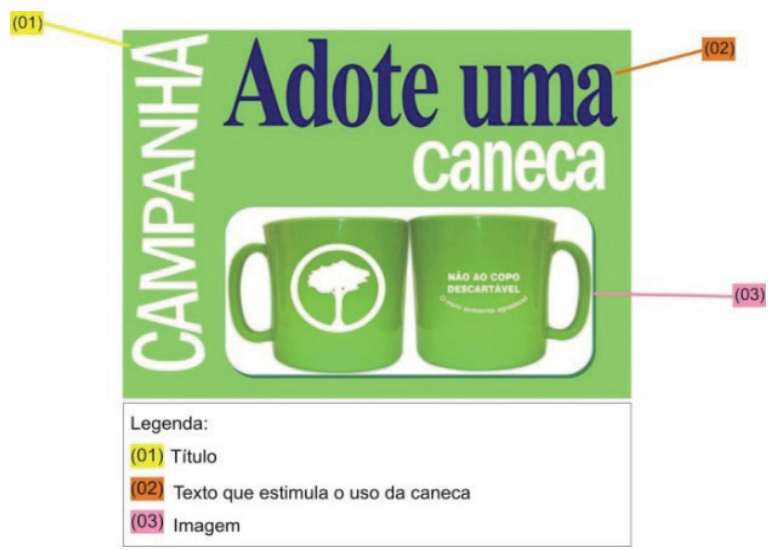

Figura 03 - Análise de cartaz

Fonte: UFOPA (2019).

Na Figura 4 observa-se o cartaz produzido para o Correio para uma campanha para o não uso de copos plásticos descartáveis, sugerindo o uso de canecas. No cartaz observa-se o título, a imagem de uma caneca verde, com as palavras "correio ic". O cartaz contém duas informações, a primeira com o seguinte texto "a redução de 3 copos descartáveis gunda frase "1 copo descartável leva aprox. 250 anos de composição". Em relação aos princípios do design gráfico, observam-se os elementos próximos uns aos outros, sobre o alinhamento foram empregados de duas formas: à esquerda e centralizado. No cartaz o contraste que prevalece é o do título, pois a fonte está maior e a palavra caneca na cor verde, e todo o restante com as letras na cor preta.

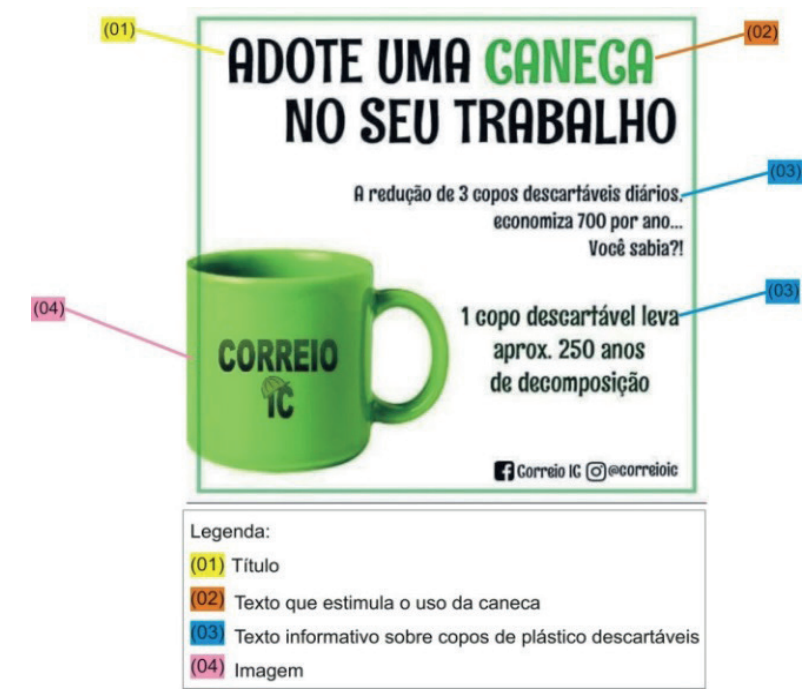

Figura 04 - Análise de cartaz Fonte: Deskgram (2019).

Na Figura 5, observa-se o cartaz produzido para o Sesi para uma campanha de conscientização para o não uso de copos descartáveis. No cartaz observa-se uma frase, imagens de copos descartáveis com a palavra "evite" com as letras na cor vermelha sobreposta na imagem dos copos. O cartaz possui a frase: "Evite o uso de copos descartáveis e contribua para uma vida sustentável", no final do cartaz há o símbolo da reciclagem com a frase "menos é mais". Em relação aos princípios do design gráfico, a imagem dos copos está acima dos elementos escritos, sobre o alinhamento foi utilizado à esquerda. No cartaz o contraste que prevalece é o fundo na cor verde. Por fim, em relação à cor, há uma faixa verde um pouco abaixo da metade do cartaz com fundo na cor branca.

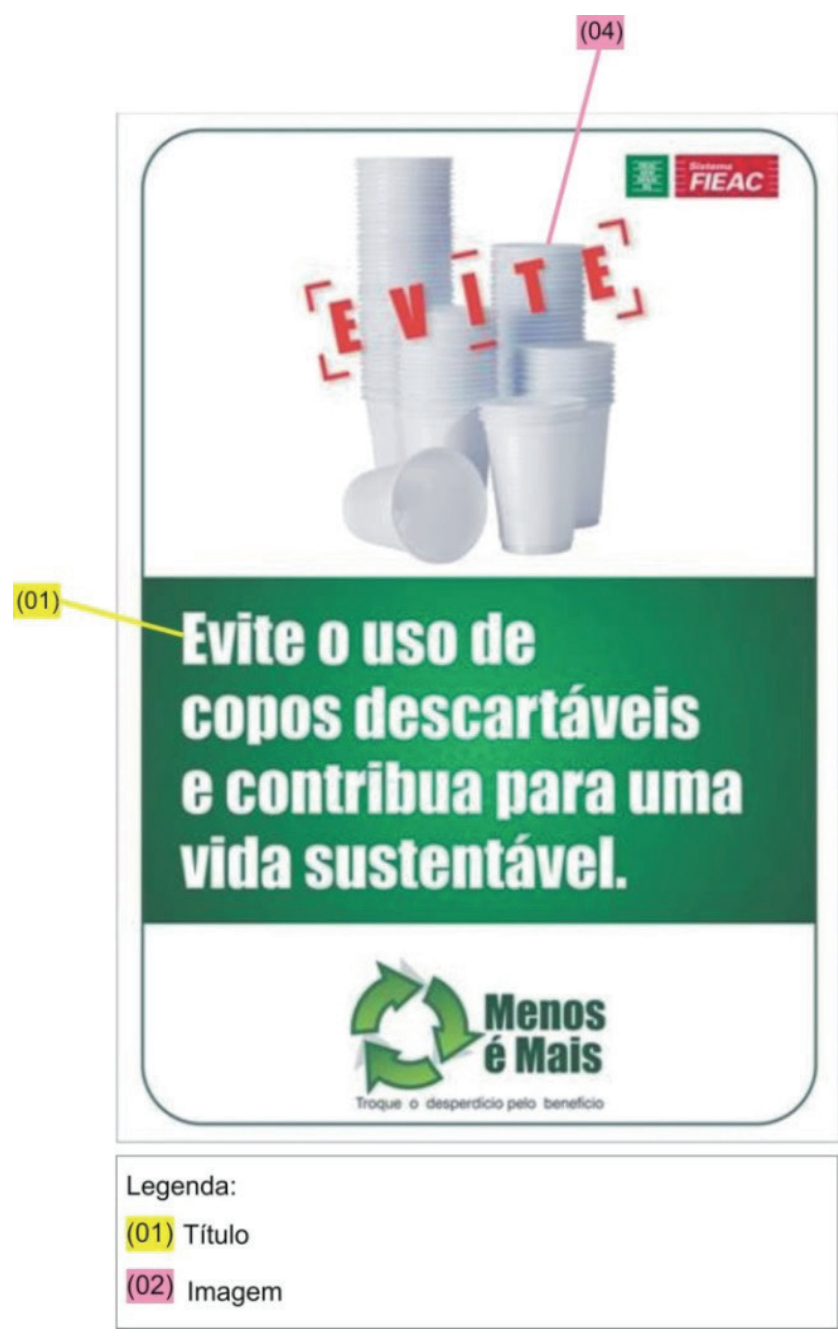

Figura 05 - Análise de cartaz

Fonte: Rede socioambiental (2019).

Na Figura 6 observa-se o cartaz produzido para a Assembleia Legislativa do Estado do Rio de Janeiro (ALERJ) para uma campanha sobre sustentabilidade, em que se observa a frase "Adote seu copo, sua caneca ou sua garrafinha. 
O copo descartável não vai ficar com ciúme". Observa-se a imagem de duas mãos, uma mão segurando um copo e a outra segurando uma caneca. Em relação ao alinhamento observa-se que os elementos estão centralizados. No cartaz o contraste que prevalece é o copo e a caneca, por possuírem uma cor mais escura do que o fundo.

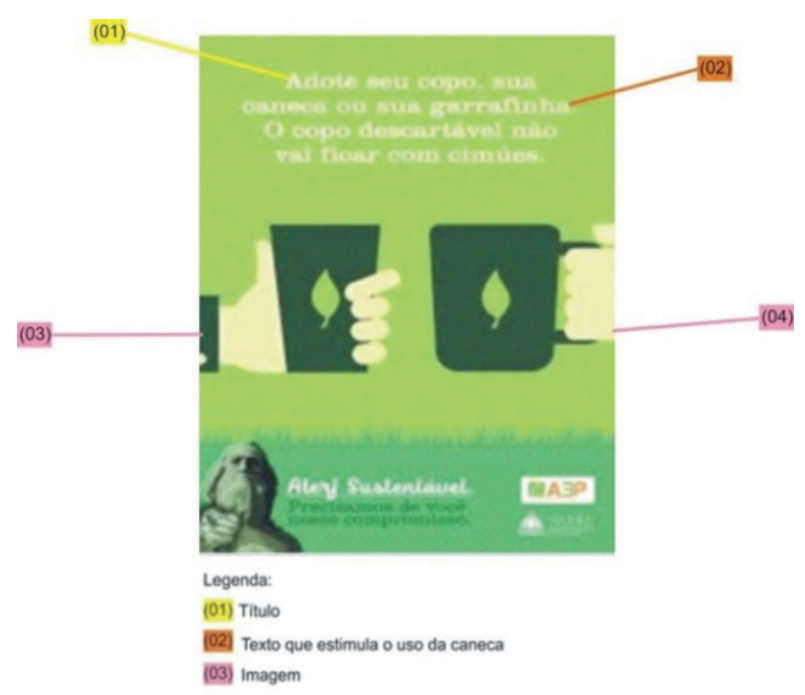

Figura 06 - Análise de cartaz

Fonte: Cartilha do aluno (2019).

De maneira geral, os cartazes possuem imagens de copos e canecas e frases que estimulam o uso de canecas. Na maioria dos cartazes a cor que predomina é a verde, pois remete a natureza e a sustentabilidade.

\subsection{Etapa II - A concepção}

Nesta etapa do projeto, foi definido o tema do projeto, que consiste na seguinte frase: "cuidando o planeta". Assim, foram pesquisadas imagens sobre impactos do plástico no meio ambiente, como plástico acumulado no mar e nas praias, conforme pode ser observado na Figura 7.

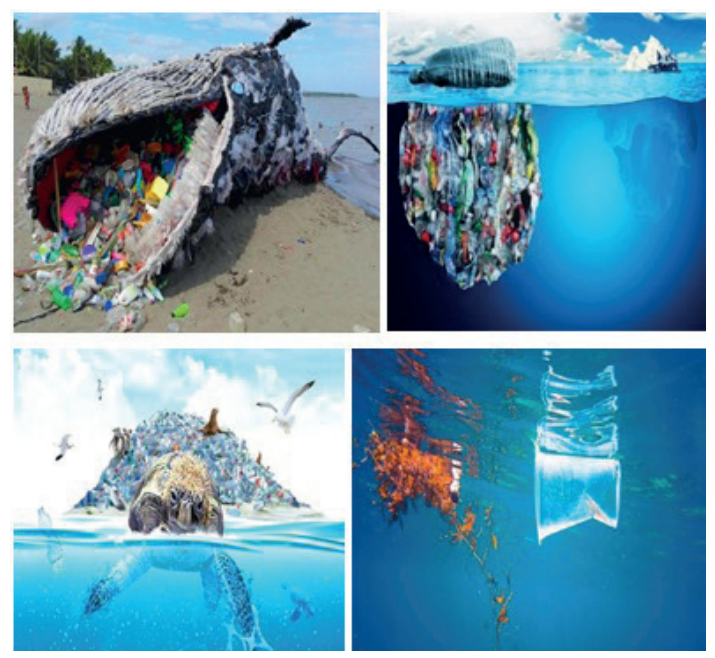

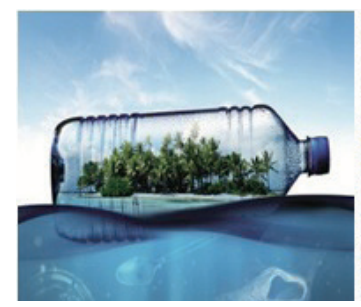

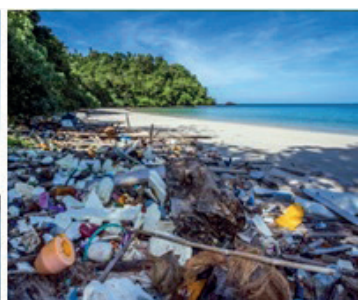

Figura 07 - Painel de imagens: Impactos do plástico na natureza

Fonte: Setor reciclagem (2019), Letras ambientais (2019), Ciclo Vivo (2019), Instituto net claro Embratel (2019), Autossustentável (2019), Cetesb (2019).

No painel da Figura 7 observam-se imagens de praias, do mar com diferentes tons de azul, animais marinhos que se alimentaram de plástico, plástico depositado na orla de praias, referencias de icebergs criados com lixo plástico, garrafas, copos, aves sobrevoando sobre os dejetos plásticos.

Além disso, foi construído um painel com imagens sobre o meio ambiente e o planeta para compor as referencias visuais para a criação dos cartazes, como pode ser visualizado na Figura 8. Foram selecionadas imagens que remetem a natureza, energia renovável e cidade arborizada.
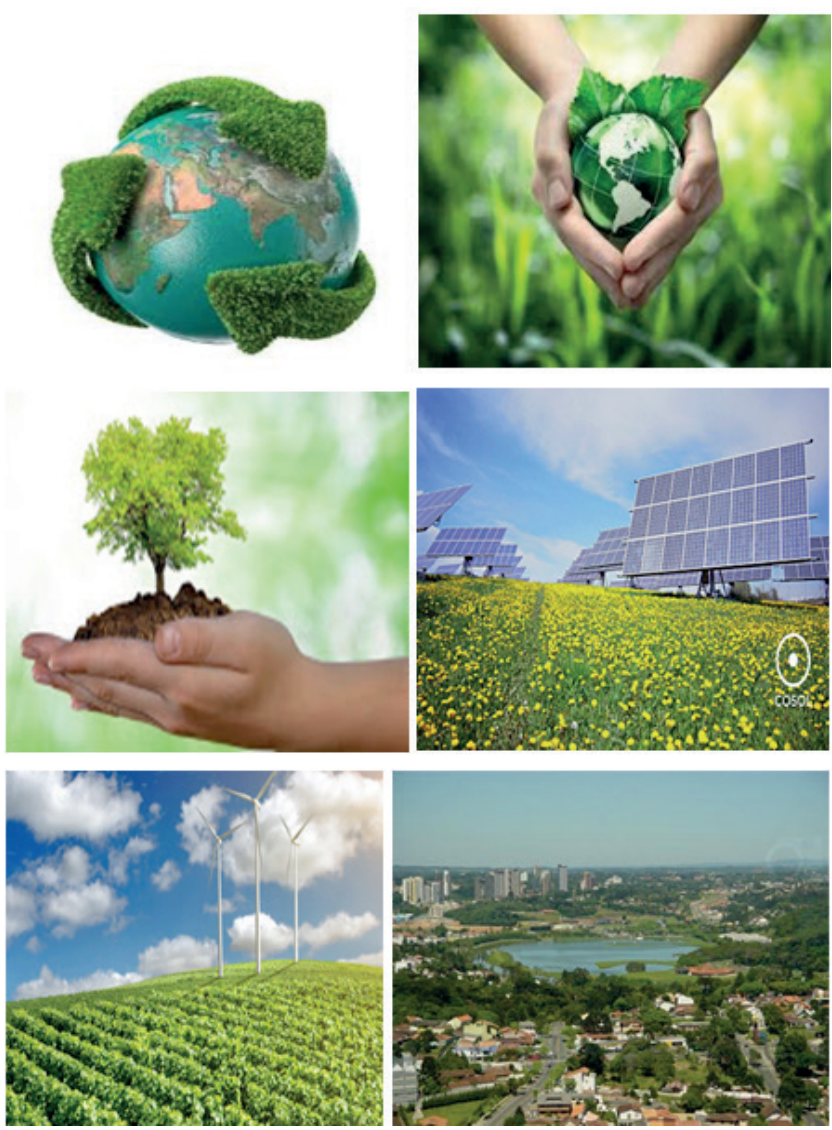

Figura 08 - Painel de imagens: 0 meio ambiente.

Fonte: Cultura Mix (2019), Família (2019), Aprendendo sobre meio ambiente (2019), Cosol (2019), Alunos online (2019), Eco desenvolvimento (2019). 
No painel da Figura 8, observam-se imagens do planeta terra, mãos segurando o planeta, mãos segurando uma planta, notam-se variados tons de verde, vegetação, painéis de energia solar, torres de energia eólica e a imagem de uma cidade arborizada.

\subsubsection{Geração de alternativas}

Através da análise dos cartazes e da pesquisa de imagens de referência sobre a temática do presente projeto iniciou-se a geração de alternativas. Nesta etapa, optou-se por criar cartazes simples e limpos, com o menor número possível de elementos, buscando equilíbrio na composição. Dessa forma, decidiu-se utilizar uma frase e uma imagem na composição do cartaz. Na Figura 9 podem-se observar esboços de alternativas da disposição dos elementos gráficos do cartaz.
Nas Figuras 10, 11, 12 e 13 observa-se a geração de alternativas, baseada no tema do projeto e no painel de imagens da Figura 8. A criação dos esboços teve como foco a imagem do planeta terra e da caneca.

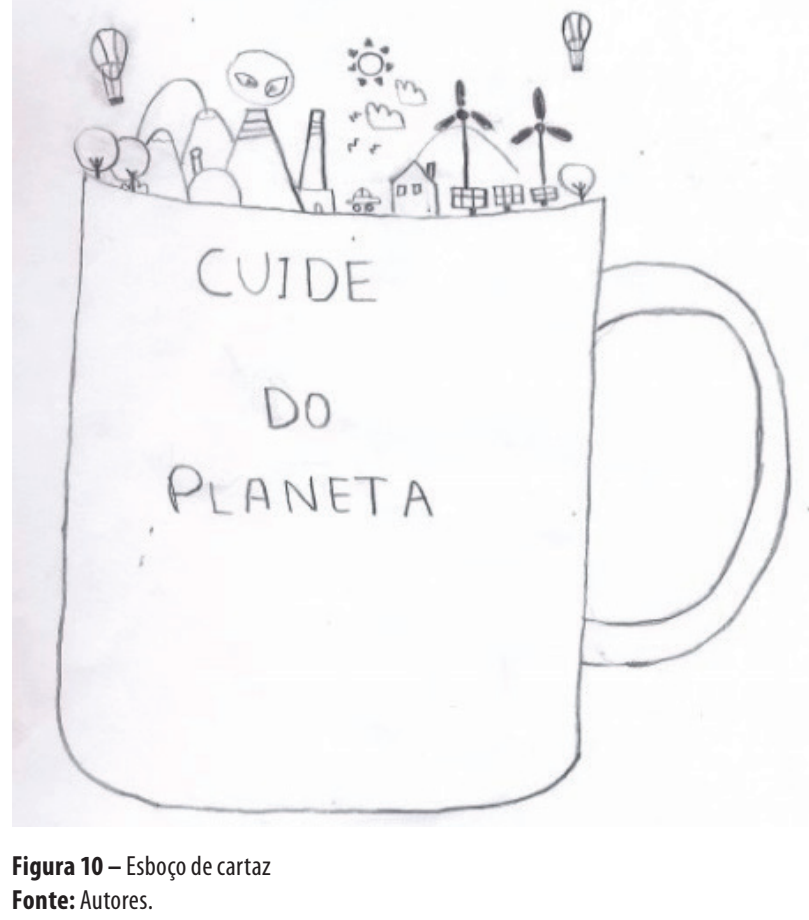

Na Figura 10 observa-se o esboço em que há o desenho de uma caneca e no centro da caneca a seguinte frase "cuide do planeta". No topo da caneca há uma cidade como se estivesse saindo do interior da caneca, nela observam-se montanhas, prédios, painéis de energia solar, torre de energia eólica, carros, árvores, balões, casas e uma paisagem.

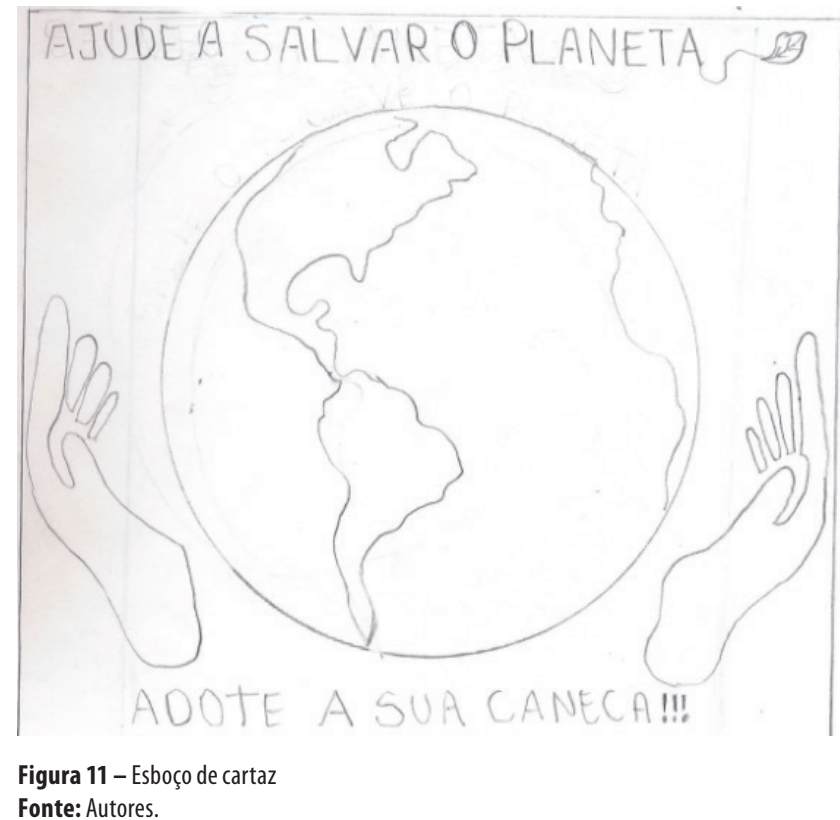


Na Figura 11 observa-se o esboço em que há a imagem de um planeta, duas mãos segurando-o, e a seguinte frase "ajude a salvar o planeta" e abaixo, uma outra frase "adote a sua caneca".

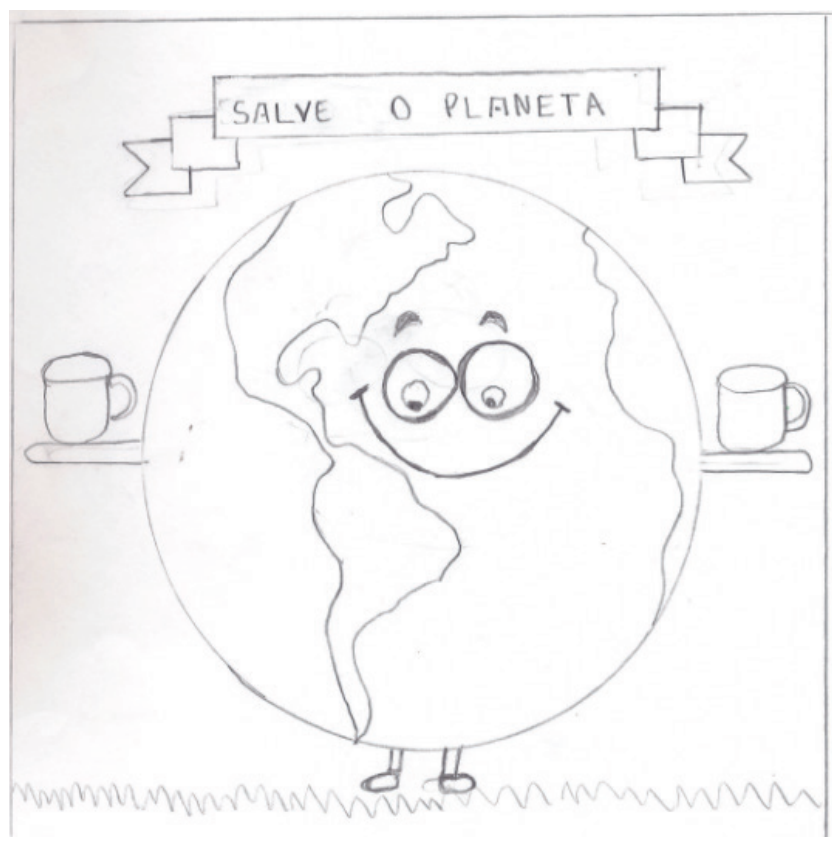

Figura 12 - Esboç̧o de cartaz Fonte: Autores.

Na figura 12, observa-se o esboço do cartaz, com uma faixa, na parte superior, contendo a seguinte frase "salve o planeta". Há o desenho de um planeta com mãos e pés segurando duas canecas em cada uma de suas mãos.

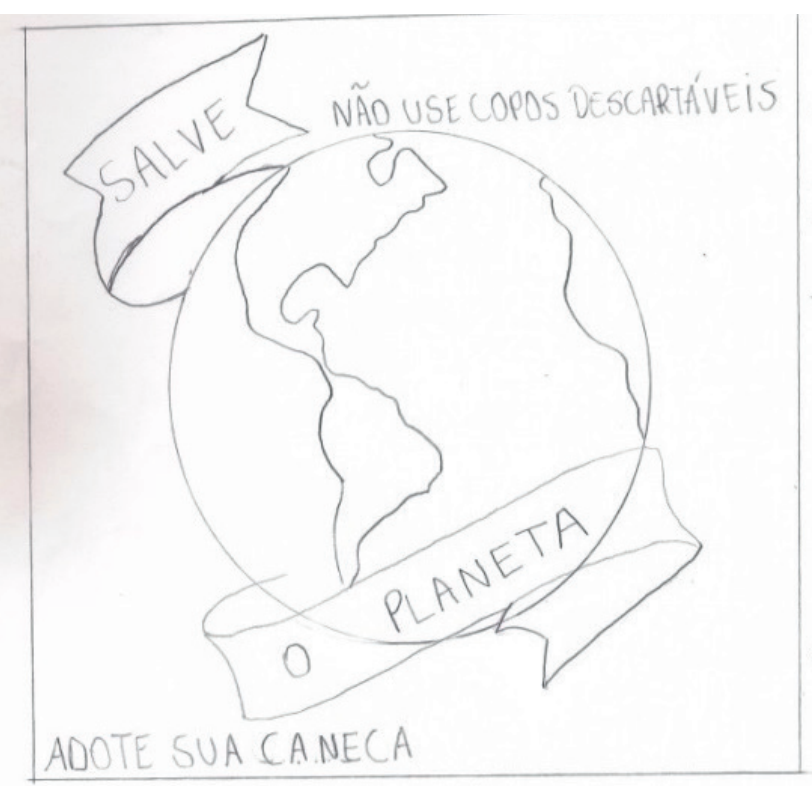

Figura 13 - Esboço de cartaz Fonte: Autores.
Na Figura 13 observa-se o desenho de um planeta com uma faixa que começa no canto superior esquerdo e termina no canto inferior direito do planeta. Na parte superior há a seguinte frase "não use copos descartáveis" e abaixo uma outra frase "adote sua caneca".

\subsection{Etapa III - A concretização}

Após a geração de alternativas, os desenhos foram digitalizados, e a partir disso, foi realizada a ilustração digital. Nesse processo, trabalhou-se com a diagramação dos elementos que compõe o cartaz, que consistem basicamente em texto e imagem, conforme se observa na Figura 14.

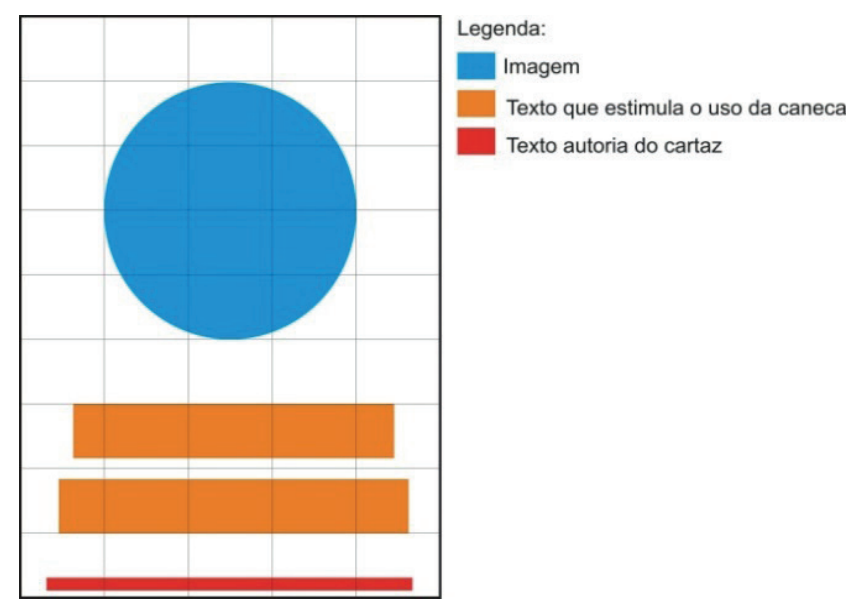

Figura 14 - Diagramação Fonte: Autores.

Na diagramação dos cartazes destacou-se a imagem, que está posicionada no centro, e logo abaixo, posicionou-se a frase que estimula o uso da caneca. Optou-se pelo alinhamento centralizado para destacar os elementos do cartaz. Em relação às cores empregadas nos cartazes, foi montada uma paleta de cores a partir das imagens dos painéis das Figuras 7 e 8 , que possuem cores em tons de azul que remetem ao mar, verde que remete a natureza, laranja e amarelo que representam o plástico, conforme pode ser observado na Figura 15.
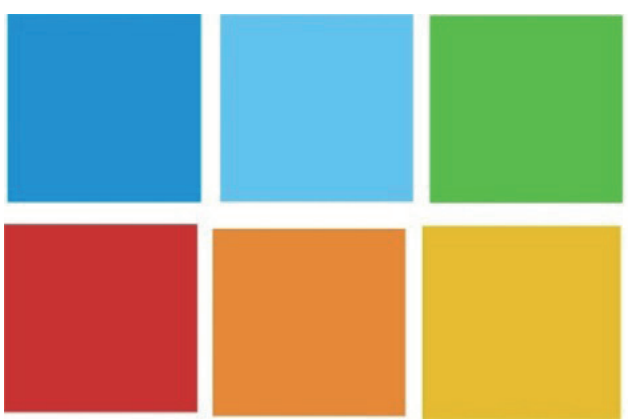

Figura 15 - Paleta de cores Fonte: Autores. 
No que diz respeito às imagens utilizadas nos cartazes, foram ilustradas no software Inkscape. Foram criadas imagens do planeta terra com braços, pernas e rosto segurando canecas (Figura 16A) as quais buscam sugerir o uso de canecas ao invés de copos plásticos descartáveis, um planeta envolto por uma faixa (Figura 16B), duas mãos e o planeta no meio delas (Figura 16C) remetendo a ideia de proteção, e uma caneca com o desenho de uma cidade com árvores saindo do seu interior (Figura 16D).

A

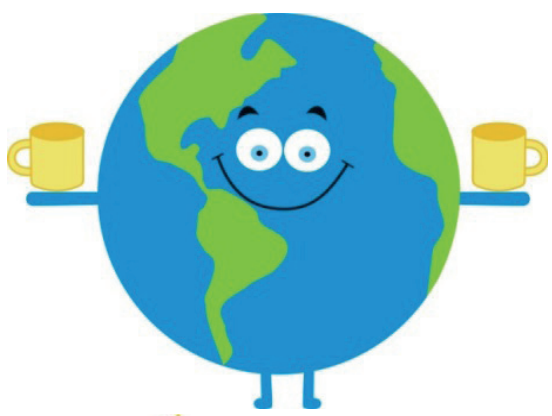

B

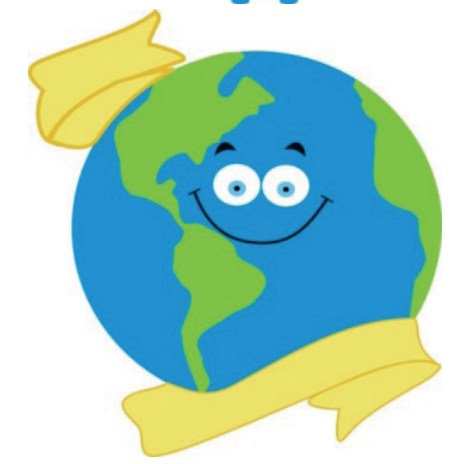

C

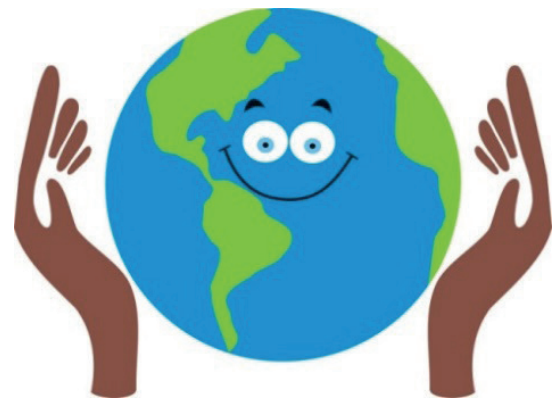

D

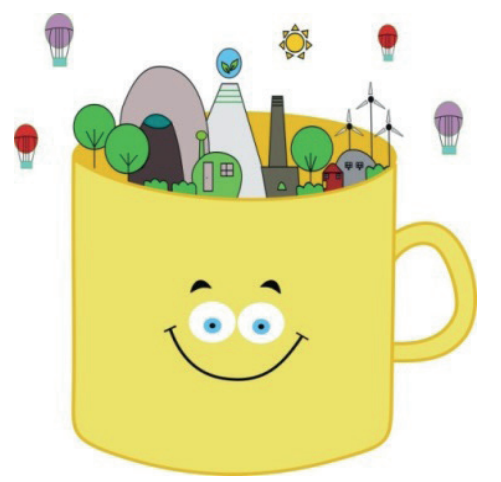

Figura 16 - llustrações: A) Planeta segurando canecas, B) Planeta com faixa, C) Planeta com mãos e C) Caneca com cidade Fonte: Autores
A tipografia selecionada para os cartazes é a Dk Lemon Yellow Sun, como pode ser visualizada na Figura 17. Foi selecionada esta fonte, pois remete a algo descontraído, despojado e divertido, para combinar com os outros elementos dos cartazes, como as cores vibrantes e as ilustrações lúdicas.

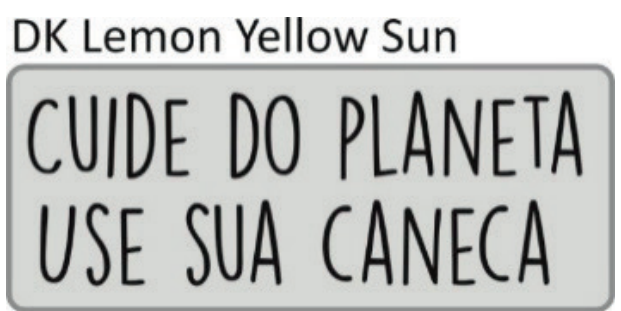

Figura 17 - Ilustrações: A) Planeta segurando canecas, B) Planeta com faixa, C) Planeta com mãos e C) Caneca com cidade Fonte: Autores.

O suporte utilizado para os cartazes foi o papel no formato A4 que é o material mais viável para esse produto, visto que o papel demora poucos meses para se decompor, o que é benéfico para os cartazes levando em conta que são temporários e logo poderão ser substituídos por outros. Nas Figuras $18,19,20$ e 21 pode-se observar os cartazes finalizados com todos os elementos conforme descrito anteriormente.

Na Figura 18 observa-se o cartaz com fundo na cor laranja. No centro há uma ilustração de um planeta segurando uma caneca em cada mão. No planeta foi aplicada a cor azul e verde e nas canecas a cor amarela. Abaixo da ilustração há a frase "Cuide do Planeta, use sua caneca" nas cores vermelha e amarela.

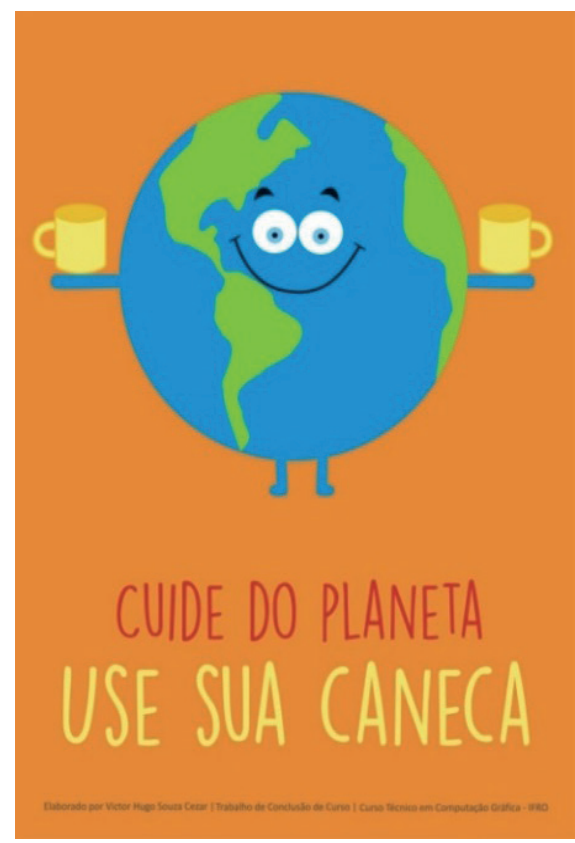

Figura 18 - Planeta segurando canecas Fonte: Autores. 
Na Figura 19 observa-se outro cartaz com as mesmas cores e frase do anterior (Figura 18). No centro há uma ilustração de um planeta envolto por uma faixa na cor amarela.

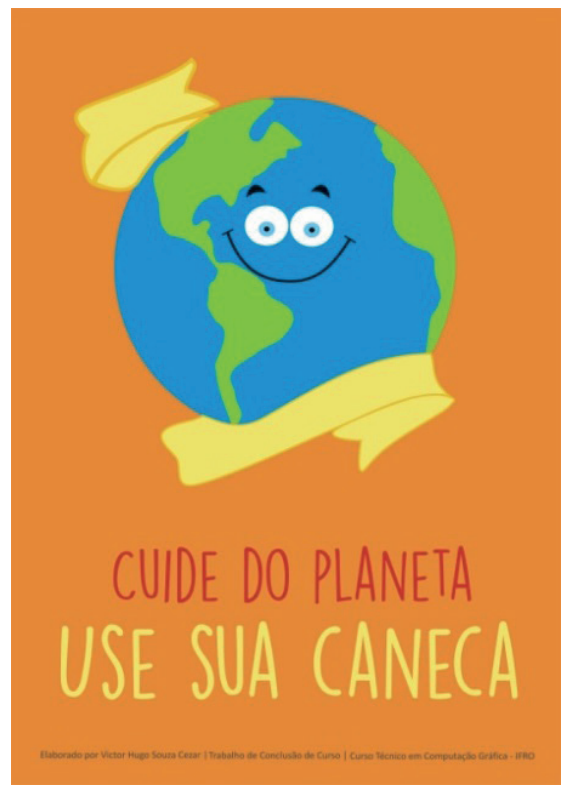

Figura 19 - Planeta com faixa

Fonte: Autores.

Na Figura 20 observa-se um cartaz com as mesmas cores e frase dos anteriores (Figuras 18 e 19). No centro há uma ilustração de um planeta envolto por duas mãos.

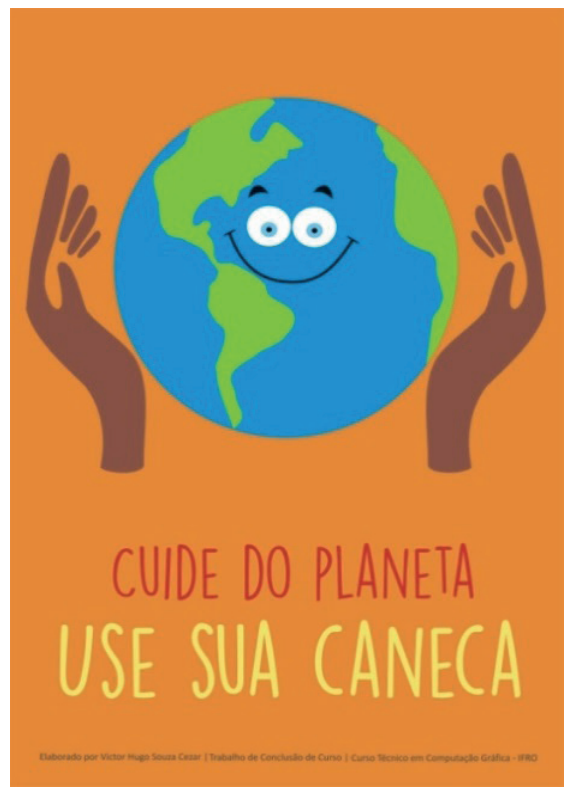

Figura 20 - Planeta com mãos

Fonte: Autores.

Na Figura 21 observa-se um cartaz com as mesmas cores e frase dos anteriores (Figuras 18, 19 e 20). No centro há uma ilustração de uma caneca com uma cidade na parte superior.

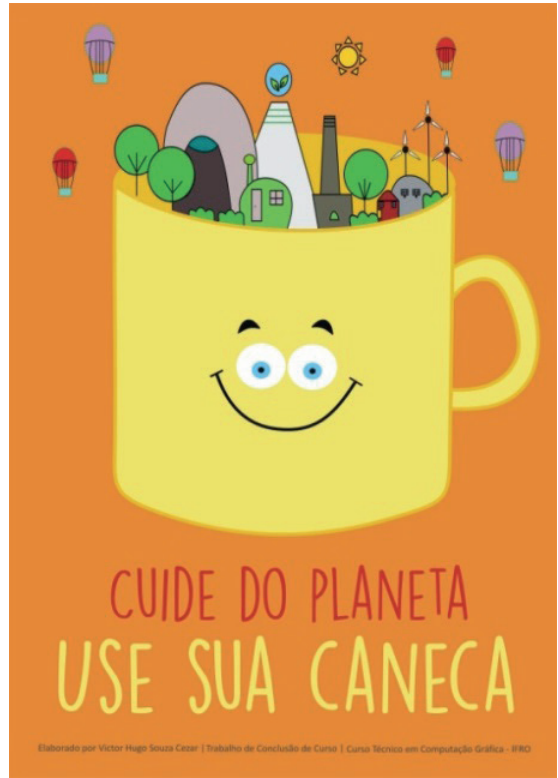

Figura 21 - Caneca com cidade Fonte: Autores.

Na Figura 22 observa-se o cartaz desenvolvido neste trabalho e seus elementos: título, texto que estimula o uso da caneca, e a imagem do planeta terra ocupando a parte central e de maior destaque.

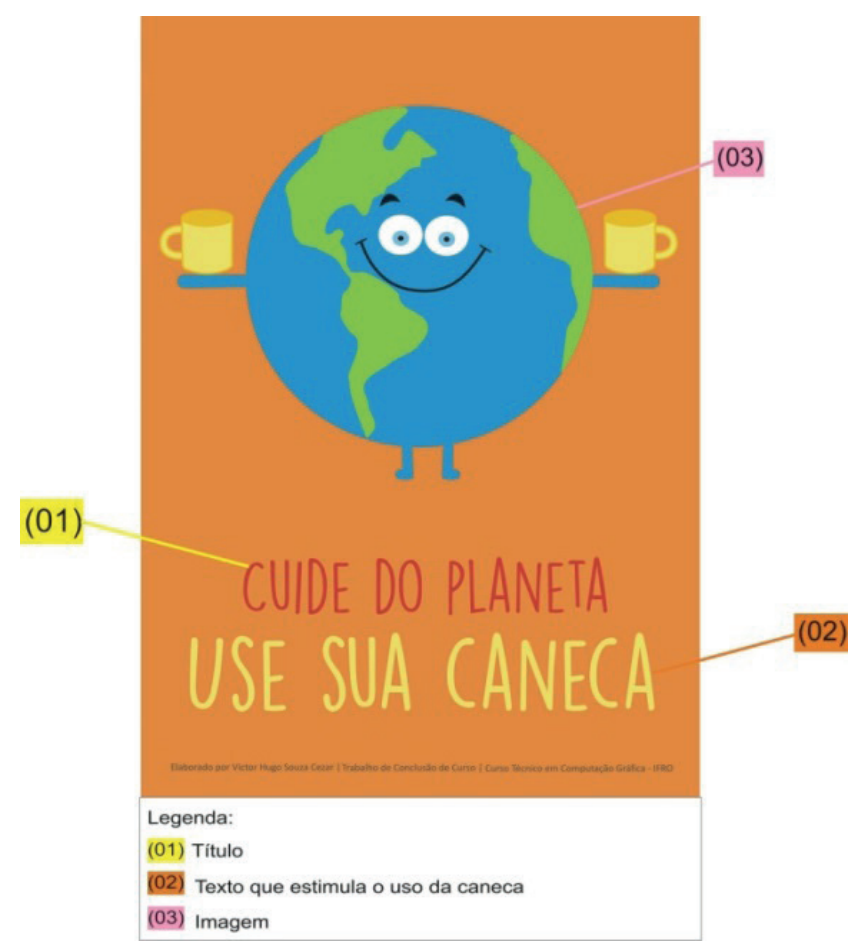

Figura 22 - Elementos do cartaz

Fonte: Autores.

Na Figura 23 observa-se a simulação do cartaz da Figura 18 em um mural. 


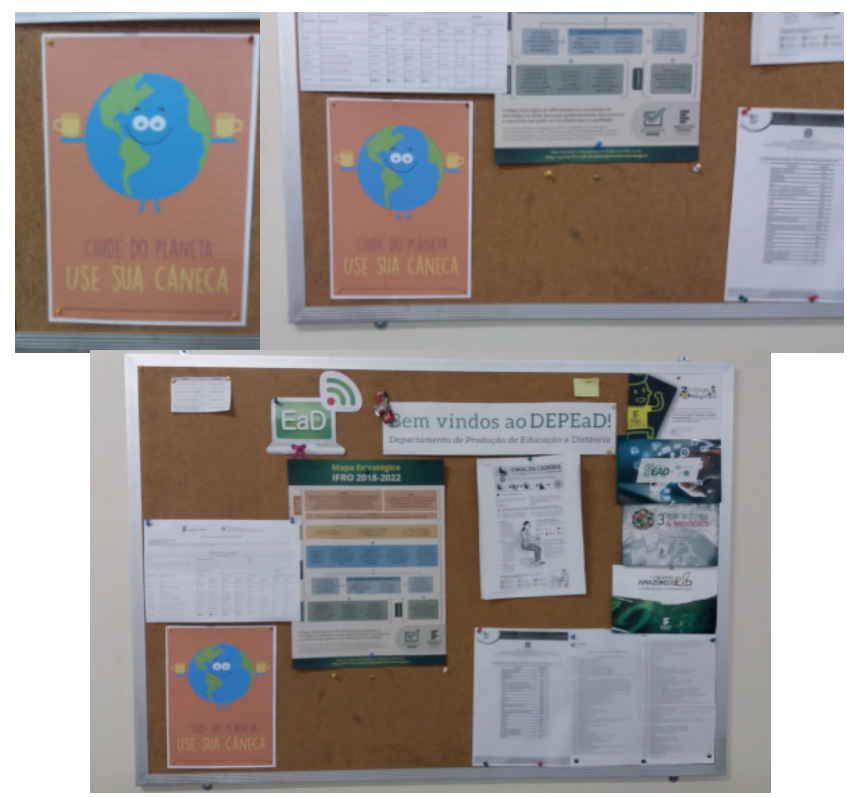

Figura 23 - Simulação de uso Fonte: Autores.

Na simulação do cartaz em um mural observa-se que por ser colorido e possuir uma ilustração ocupando grande parte do cartaz, destaca-se em relação aos outros informativos do mural. Além do mural os cartazes podem ser inseridos em outros locais públicos.

\section{CONSIDERAÇÕES FINAIS}

Este trabalho teve como principal objetivo a criação de uma série de cartazes como ferramenta para a conscientização da diminuição do uso excessivo de copos plásticos descartáveis, ressaltando a importância do uso de canecas reutilizáveis em instituições públicas e privadas. $\mathrm{O}$ desenvolvimento do projeto dos cartazes teve como base a metodologia projetual de Fuentes (2006), dividida em três etapas: a pesquisa, a concepção e a concretização, que objetivaram nortear o processo criativo do design. Para a criação dos cartazes foi utilizado o tema "cuidando o planeta". Assim, os cartazes foram desenvolvidos a partir de ilustrações de um planeta e caneca no centro e uma frase que estimula o uso de canecas, posicionada abaixo da ilustração.

A expectativa com a criação desses cartazes é estimular a reflexão sobre a importância da adoção de canecas reutilizáveis e a diminuição do uso de copos plásticos descartáveis. Porém, ainda caminha-se com passos lentos em relação a essa temática, pois os copos plásticos descartáveis são usados excessivamente, e quando descartados na natureza causam impactos. Desse modo, os cartazes constituem-se em uma ferramenta que pode contribuir para a diminuição do uso de copos plásticos descartáveis na medida em que estimula o uso de canecas.

\section{REFERÊNCIAS}

AUTOSSUSTENTAVEL. $\mathbf{O}$ que você pode fazer para reduzir o consumo do plástico. Disponível em: http://autossustentavel.com/2018/06/o-que-voce-podefazer-para-reduzir-o-consumo-de-plastico.html. Acesso em 11 de junho de 2019.

ALUNOS ONLINE. Recursos naturais. Disponível em: https://alunosonline.uol.com.br/geografia/recursos-naturais.html. Acesso em 11 de junho de 2019.

APRENDENDO SOBRE MEIO AMBIENTE. Conhecendo o meio ambiente e a natureza. Disponível em:

http://aprendendosobremeioambiente.blogspot. com/2016/05/conhecendo-o-meioambiente-natureza-e.html. Acesso em 11 de junho de 2019.

CARTILHA DO ALUNO. Sustentabilidade. Disponível em: $\quad$ file:///C:/Users/Aluno/Downloads/cartilha\%20 a3p\%20(2).pdf. Acesso em 10 de abril de 2019.

CETESB. Entenda o impacto do plástico nos oceanos e no meio ambiente. Disponível em: https:// cetesb.sp.gov.br/proclima/2018/07/24/entenda-o-impacto-do-plastico-nosoceanos-e-no-meio-ambiente/. Acesso em 10 de abril de 2019.

CICLO VIVO. Tartarugas, recursos reutilizáveis. Disponível em: https:/ciclovivo.com.br/inovacao/negocios/rod-stewart-dubla-tartaruga-produtosreutilizaveis/. Acesso em 11 de junho de 2019.

CULTURA MIX. Resumo sobre o meio ambiente. Disponível em: http://meioambiente.culturamix.com/ natureza/resumo-sobre-meio-ambiente. Acesso em 11 de junho de 2019.

COSOL. Economia dos recursos naturais e energéticos e a solução para os problemas ambientais. Disponível em: https://www.cosol.com.br/blog/a-economiados-recursos-naturais-e-energticos-e-a-soluo-para-os-problemas-ambientais. Acesso em 11 de junho de 2019.

DESKGRAM. Não ao copo descartável. Disponível em: https://deskgram.net/explore/tags/naoaocopodescartavel. Acesso em 10 abril de 2019.

ECYCLE. Impacto ambiental do lixo plástico. Disponível em: https://www.ecycle.com.br/6251-impacto-ambiental-do-lixo-plastico.html. Acesso em 19 de junho de 2019.

ECO DESENVOLVIMENTO. Lista das cidades mais verdes. Disponível em: http://www.ecodesenvolvimento. org/noticias/organizacoes-listam-as-cidades-maisverdes-do. Acesso em 11 de junho de 2019. 
FAMILIA. Preservação da natureza. Disponível em: https://www.familia.com.br/preservacao-da-natureza-como-ensinar-as-criancassobre-a-poluicao-e-o-meio-ambiente/. Acesso em 11 de junho de 2019. FUENTES, R. A prática do design gráfico: uma metodologia criativa. São Paulo: Rosari, 2006.

INSTITUTO NET CLARO EMBRATEL. Imagens. Disponível em: https://www.institutonetclaroembratel.org.br/cidadania/nossasnovidades/noticias/ aproximadamente-95-dos-residuos-solidos-das-praias-saomateriais-plasticos-afirma-professor/. Acesso em 11 de junho de 2019.

LETRAS AMBIENTAIS. Imagens. Disponível em: https://letrasambientais.com.br/posts/poluicao-plastica:-impactos-sobre-a-saude-doplaneta. Acesso em 11 de junho de 2019.

ROQUE GONZALES. Administração municipal lança campanha interna para reduzir o uso de copos descartáveis. Disponível em: https://roquegonzales.rs.gov.br/site/noticias/geral/21093-administracao-municipallanca-campanha-interna-para-reduzir-o-uso-de-copos-descartaveis. Acesso em 10 de abril de 2019.

REDE SOCIOAMBIENTAL. Cartaz. Disponível em:

http://rede.socioambiental.zip.net/arch2010-1114_2010-11-20.html. Acesso em 10 de abril de 2019. SETOR RECICLAGEM. Cartaz. Disponível em: http://www.setorreciclagem.com.br/legislacao/ senado-aprova-o-fim-dos-plasticosdescartaveis/. Acesso em 11 de junho de 2019.

TRIUNFO. Agricultura e meio ambiente. Disponível em: http://www.triunfo.pe.gov.br/category/agricultura-e-meio-ambiente/. Acesso em 10 de abril de 2019.

UNESC. Cartaz. Disponível em: http://www.unesc.net/portal/aicom/blog/40571. Acesso em 19 de junho de 2019.

UFOPA. Adote uma caneca, campanha pela redução de copos descartáveis na ufopa. Disponível em: http://www2.ufopa.edu.br/ufopa/noticias/2014/ novembro/adote-uma-canecacampanha-pela-reducao-de-copos-descartaveis-naufopa/image/image_view_fullscreen. Acesso em 10 de abril de 2019. WILLIAMS, R. Design para quem não é designer: noções básicas de planejamento visual. São Paulo: Callis, 2009.

\section{AUTORES}

ORCID: https://orcid.org/0000-0001-5568-4620

ELIANA PAULA CALEGARI, Dra. | Instituto Federal de Rondônia - IFRO | Computação Gráfica | Porto Velho, RO | Brasil | Correspondência para: Avenida Governador Jorge Teixeira - 3146, Setor Industrial, Porto Velho - RO, 76821002 | e-maill: elianapaulac@gmail.com

ORCID: https://orcid.org/0000-0002-4109-5574

VICTOR HUGO SOUZA CEZAR | Instituto Federal de Rondônia - IFRO | Computação Gráfica | Porto Velho, RO | Brasil | Correspondência para: Avenida Governador Jorge Teixeira - 3146, Setor Industrial, Porto Velho - RO, 76821002 | e-maill: hugovictor4885@gmail.com

\section{COMO CITAR ESTE ARTIGO}

CALEGARI, Eliana Paula; CEZAR, Victor Hugo Souza. Criação de Cartazes como Ferramenta para Diminuição do Uso Excessivo de Copos Plásticos Descartáveis. MIX Sustentável, [S.I.], v. 5, n. 4, p. 41-51, out. 2019. ISSN 24473073. Disponível em:<http://www.nexos.ufsc. br/index.php/mixsustentavel>. Acesso em: dia mês. ano. doi:https://doi.org/10.29183/2447-3073.MIX2019. v5.n4.41-51.

DATA DE ENVIO: 02/09/2019 
